Corazn Celado (Larvatus Prodeo), 2001, e Instante Fugaz, 2001, son dos obras del artista Fernando Sinaga que exponen estructuras creativas características de la estética del arte contemporáneo. En su libro La Era Neobarroca, Omar Calabrese define la emergencia de estas estructuras como un espíritu de nuestro tiempo o, como señala Paolo Fabbri, una "estética social" que se manifiesta por razones de gusto e interés mediante propiedades afines a las barrocas, en cuanto a sus estructuras y relaciones formales, semánticas y receptivas. En este texto coincido con Calabrese al referirse a estos patrones neobarrocos como características que no son nuevas, tan sólo modelos más afines con la contemporaneidad, estructuras que excitan el interior socio-cultural y que nos ayudan a comprender el tiempo metamórfico, abierto e incierto en que se manifiesta.

Palabras claves: arte, sombra, contemporaneidad 


\section{El neobarroco a través de las sombras de Fernando Sinaga}

Fran Miguens

FERRO

Corazn Celado (Larvatus Prodeo), 2001, e Instante Fugaz, 2001, são duas obras do artista Fernando Sinaga que expõem estruturas criativas características da estética da arte contemporânea. Em seu livro La Era Neobarroca, Omar Calabrese define o surgimento destas estruturas como um espírito de nosso tempo ou, como foi observado por Paolo Fabbri, uma "estética social" que se manifesta por razões de gosto e de interesse através de propriedades próximas ao Barroco, assim como suas estruturas e relações formais, semânticas e receptivas. Neste texto, concordo com Calabrese quando se refere a esses padrões neobarrocos como características que não são novas, mas apenas modelos mais próximos ao contemporâneo, estruturas que excitam o interior sócio-cultural e que nos ajuda a compreender o tempo metafórico, aberto e incerto em que se manifestam.

Palavras-chave: arte, sombra, contemporaneidade 


\section{Introducción}

Este breve estudio se adentra en la comprensión de determinadas obras plásticas como manera de hallar algunas de las características más destacables del arte actual. Las dos obras de arte seleccionadas de Fernando Sinaga participan, a mi juicio, plásticamente de las propuestas teóricas del libro La Era Neobarroca de Omar Calabrese. De este modo y partiendo de tales propuestas teóricas así como de los niveles de lectura formal, semántico y receptivo aplicados a las obras Corazn Celado (Larvatus Prodeo) e Instante Fugaz llegaremos a una serie de conocimientos artísticos, que también confluyen con pensamientos estéticos, científicos y metafísicos, de índole barroca y que llegan a conformar una visión particular de nuestro tiempo actual.

\section{Metodología}

Se desarrolla un análisis comparativo entre los conceptos expuestos por Omar Calabrese en su obra La Era Neobarroca y las características que se dan a nivel formal, o conjunto de características técnicas y de presentación; semántico, o significado de los signos y sus combinaciones; y receptivo o posición del espectador ante las obras del artista Fernando Sinaga Corazn Celado (Larvatus Prodeo) e Instante Fugaz, ambas del 2001. Los conceptos a tener en cuenta son:

Lo fragmentario, como método compositivo.

La inestabilidad y la tendencia al caos, como síntomas de lo complejo e indeterminado.

La imprecisin y la tendencia al Imite de lo visual, como reordenamiento de las fronteras establecidas.

La teatralidad, conferida por el uso de recursos como la distorsión, la excentricidad y la exageración.

La nada y el monstruo, como estadios que cuestionan cualquier ideal perpetuo y seguro.

Lo oculto y el enredo, tanto como método compositivo como de discursivo. 


\section{Análisis}

\subsection{Formal}

Las creaciones Corazn Celado (Larvatus Prodeo), 2001, e Instante Fugaz, 2001, nos ofrecen las imágenes fotográficas en blanco y negro de unas formas que, aunque poseen cierto anonimato otorgado por la oscuridad de sus características físicas, se pueden identificar con el autor y un enrejado o celosía en sombra. Éstos no se describen en toda su extensión sino que se muestran fragmentados, entrecortados o en escorzo. Sin embargo, algunos puntos de las imágenes, como en los cruces entre figura humana y celosía o en los ángulos donde coinciden los objetos con sus sombras, llegan a ser confusos y contrastan con la simpleza visual de las imágenes.

La estaticidad de las imágenes, que semejan haber sido atrapadas en el tiempo y en el plano bidimensional en el transcurso de alguna acción, y sus tonalidades apagadas confieren al conjunto un aura cercana al hieratismo. La neutralidad del color blanco de la estancia en la que se inscriben sintoniza con el claroscuro y la sutil gradación tonal de los degradados. La apariencia, tanto de la composición como de la imagen final es teatral, sencilla y sin ornamento.

En ambas obras el artista ha introducido los propios referentes de las sombras dentro de la fotografía, desvelando el origen de tales artificios, con fines compositivos y simbólicos. Observamos dos representaciones dentro de la misma imagen, a saber: la representación fotográfica de la celosía y de la mano de forma realista y de sus correspondientes sombras. De este modo se establece el diálogo interno entre la representación del referente y su sombra.

Así, en Instante Fugaz, el punto de vista elegido para la fotografía provoca que la sombra de la mano llegue a tocar la de la celosía, algo que no es posible en sus homónimos físicos, dándonos ya unas pistas sobre la simbología de las sombras y su capacidad para introducirnos en otros mundos abiertos a partir de fenómenos físicos. Es por ésto que el autor acaba por situarse más como escenógrafo que como documentalista 
puesto que sus formas o figuras codificadas terminan por trascender la exposición física.

Asimismo evidencia el uso en la contemporaneidad de recursos clásicos de la representación como la perspectiva, y su necesidad de un punto de vista determinado, o las sombras, para poner de relevancia la correlación entre la dicotomía luz/ sombra, verdad/apariencia y reflexionar sobre los discursos que se esconden en las sombras como imágenes de la duda.

La relación entre fotografía y realidad viene determinada por la utilización del medio fotográfico como modelo perceptivo que se ausenta del mundo progresivamente hasta alejarse de / (SINAGA, 2005, p. 169) en cierto modo negando su uso como sistema retiniano. Es decir, fotografía y sombra son huellas, índices de una realidad física, específica y relativa, o verdades a medias. Se comportan como fijación, registro y archivo de un instante irrepetible, conservándolo en el tiempo, pero van más allá de la mimesis de lo presente apuntando hacia la obligada ausencia de todo.

En cuanto a la relación entre los recursos formales utilizados por Sinaga en éstas dos obras y las propuestas analíticas de Calabrese en La Era Neobarroca destacaría:

- Lo fragmentario, recurso que permite al autor centrar la atención sobre lo esencial y crear expectativas hacia el espectador. Calabrese, en un sentido más global, en su explicación sobre el detallismo y la fragmentaci$n$ concluye que todo producto artístico así dispuesto, singularizado, termina por constituir un elemento autónomo y material para posteriores usos y estudios. Las obras sufren un proceso anacrónico y de ruptura hacia todo orden y discurso originario e histórico encaminándose hacia la continua re-lectura, el consumo y la anulación memorística. Dicha producción de detalles y fragmentos va unida al desarrollo y velocidad tecnológica. De este modo las fotografías de Sinaga se sitúan en un estadio intemporal, autónomo y sumido en la pluralidad narrativa puesto que se hayan desnaturalizadas, separadas de su contexto original y albergadas en un espacio expositivo que invita, con su neutralidad, a la apertura 
significativa y receptiva de la obra.

- La inestabilidad y la tendencia al caos a partir de la deliberada amalgama y yuxtaposición entre los motivos, enrejado y figura humana, crea un conjunto visualmente complejo, reflejando con ello un pensamiento característico de la situación cultural de la época. En la actualidad éstas representaciones inestables y caóticas emergen en un tiempo donde se desarrollan diversas teorías científicas, como las Teoras de las Catstrofes; el Principio de Incertidumbre (Heissenberg), la Lgica Borrosa (Bertrand Russell) o las Teoras del Caos (Yorke y Yien Li), que abogan por la relatividad, complejidad e incertidumbre tanto de los acontecimientos como de sus estructuras.

- La imprecisión como apariencia visual. Estas obras de Sinaga semejan velos etéreos que parecen apropiarse de antiguos procedimientos como los daguerrotipos, el pictorialismo fotográfico o el sfumato leonardesco los cuales daban apariencia de levedad y fragilidad a los motivos retratados. Instante Fugaz y Corazn Celado (Larvatus Prodeo) no se centran solamente en los personajes sino en la totalidad de cada composición; figura y atmósfera componen matices difuminados y porosos en los que las cosas parecen fantasmas quebradizos y huidizos entremezclándose los unos con otros. La recepción se vuelve un tanto difusa e intuitiva. Sin embargo tal imprecisión no es ingenua sino que está en consonancia con las estrategias neobarrocas encaminadas hacia la Nada. Son restos, un casi nada, formas aproximadas que escapan a la estabilidad proponiendo la ruptura y el enigma. Poseen una cierta raíz nihilista y lúdica ya existente en las "vanitas vanitatum" barrocas cuyos objetos se hallan bajo características como la indistinción, la ausencia, la desfiguración y la aniquilación ("annihilatio").

- La naturaleza teatral de las imágenes descritas. Instante Fugaz y Corazn Celado (Larvatus Prodeo) son obras cuyos figuras y objetos evidencian la deformación y la 
elasticidad de sus límites y excesos tanto en lo formal como en lo simbólico. Para Omar Calabrese esto enlaza con un emergente gusto que termina por desplazar sus propios límites, regenera el propio sistema cultural, para aceptar tales comportamientos y exponerlos como cotidianos y normales. Sus discursos y procesos ofrecen visiones del "arte y vida" y de la identidad individual como apariencia perpetua. Todo ello bajo encuadres y puntos de fuga forzados, exagerados o brbaros, muy típicos del tardo-renacimiento, manierismo y barroco, que provocan lo socialmente establecido poniendo en crisis juicios y valores. Dichas estructuras semejan Test de Rorschach, aluden a las teorías psicoanalíticas, al doble negativo y al inconsciente colectivo como en el cine expresionista alemán de los años 20. Calabrese las define como "monstruos", estructuras irregulares o que desplazan la lógica racional estipulada pero que nos atraen a la vez por su carácter enigmático y desafiante. Estos monstruos sublimes ceden en la actualidad parte de su carácter terrorífico en favor de la puesta en crisis de la oposición entre realidad y ficción, construyendo tipologías hacia lo múltiple e indeterminado de nuestras homologaciones sobre lo feo y lo bello, lo bueno y lo malo, lo conforme o lo deforme, sumiendo cualquier juicio de valor en la incertidumbre.

\subsection{Semántico}

Aunque todas las sombras proceden de la proyección y el contacto con la luz, bien sea natural o artificial, esta mancha sencilla y que antiguamente se atribuía a la falta de habilidad es el gérmen de la mitología de las artes en Plinio, las apariencias erróneas y negativas de Platón, los contornos recortados de Étienne de Silhouette o los fotogramas de Man Ray. El discurso icónico y metafórico no puede ser escindido de tales referentes ya tradicionales aunque, por razones de acotación de este trabajo de investigación, sólo pueden ser mencionados. Un ejemplo de referente: Narciso. Fernando Sinaga lo alude como 
método de indagación artística, un narcisismo que interroga no sólo el proceso creativo sino al propio sujeto artístico. Para la mitología filosófica simboliza al amante de las apariencias y lo fugaz, condenado, según Plotino, a vagar constantemente alerta para capturar los fantasmas, las sombras, de las cosas y sucesos en su incesante desaparecer. Situarse en el espejo de Narciso es renunciar a su final trágico, es alejarse del victimismo afrontando, en su representación, la verdad del tránsito de las cosas. Un placer negativo en el que se respira el deseo insatisfecho, la imposibilidad, lo inalcanzable. La única morada que puede habitar el espectador es la del voyeur en su vacío, habitar la ruina y el silencio. Sin embargo, y en consonancia con el pensamiento de Heidegger, Cage, Sartre o Smithson, no es la Nada ni la falta neutral sino un lugar libre para habitar como potencia. Un proceso de interiorización y transformación mediante el cual los individuos y las cosas se identifican en su reflejo y su alteridad.

De este modo el avanzar enmascarado, recordando al filósofo francés René Descartes, a San Juan de la Cruz y el Hermetismo, del personaje fotografiado, es la imagen de la penumbra literal y metafórica que impide asomarse claramente a la verdad que encierra. Los propios elementos figurativos de la fotografía constituyen ya un lugar para la ocultación (la celosía). La sombra denota y connota ocultamiento, pérdida de conocimiento y de identidad, oposición a la luz de la lógica, a la luz de las ideas platónicas y de la realidad como conocimiento objetivo. Pero también es morada protectora, velo que oculta y atmósfera que envuelve a las cosas en el secretismo. Como tal no son un mero referente de la realidad exterior sino construcciones de la expresión artística propia, una escenificación de la realidad interior.

Fernando Sinaga pretende con ello sumirnos en la ambigüedad reflexiva de las máscaras; que por un lado nos protegen del otro (en este caso el observador) y por el otro nos esconden de nosotros mismos. Mediante ésta sombra el artista parece indicarnos una autoprotección relegando el encuentro consigo mismo, desplazando su esencia y el restablecimiento con las heridas del alma. Desarrolla así un trabajo crítico sobre el disfraz 
como nueva piel que, como los materiales simbólicos de Joseph Beuys, nos visten y nos protegen, pero que también nos alejan de la vida real, sumiéndonos en vidas idílicas, sueños y proyecciones. La escisión de su sombra sugiere el gesto de arrancarse la piel como disfraz, como velo de la era mediática que nos impermeabiliza y nos separa de lo interno en favor de una perpetua exterioridad. Un despertar de la amnesia, de la mirada de la pantalla industrial, de la cultura del simulacro y el espejo artificial, desde el propio sistema de las imágenes, mediante la ruptura o perforación de la mirada impuesta. Sombras que señalan un estado virtual que desplaza al Yo hacia un pliegue de realidades y a la nulidad en donde la alteridad es un fantasma que se aleja de sí mismo e indica un retorno imposible. Esa tendencia hacia las metamorfosis de los cuerpos y el flujo constante entre pliegues de la realidad, la idea de un cosmos inestable, entra en sintonía con los estudios de llya Prigogine sobre la disipacin (PRIGOGINE \& STENGERS, 1994, p. 181). La lógica de la sombras de Fernando Sinaga comparte con las teorías científicas de la complejidad el deseo de poner en evidencia la relatividad, la pluralidad y la fragmentación del universo y el caos y la indeterminación como génesis en potencia, pero se comportan como un wegweiser o indicador de caminos más que la resolución al enigma; espacios reflexivos que ilustran la distancia mínima y abismal que separa el deseo de la realidad.

Félix Duque menciona en su análisis de la obra de Fernando Sinaga ${ }^{1}$ que los procesos de evacuación del Yo se tornan recuerdo, memoria y falta. Procesos compuestos por huellas de restos etéreos, sombras y recuerdos, que se muestran ambiguos puesto que sobran a la vez que conforman la esencia de Uno mismo. Sin embargo, estos procesos de vaciamiento (Kénosis) al mismo tiempo que se produce un continuo echar fuera y exiliarse de sí mismo también se conforman las identidades, de forma que el dejarse se convierte en un llegar a ser.

La educación represiva es la responsable de haber creado los "monstruos interiores" que devoran el alma y hacen el individuo un ser dividido esencialmente. El artista es aquel que manifiesta la energía de ese "doble ser", un Cor Duplex que aprende a comunicarse consigo mismo a través de sus creaciones y termina por crear 
una circulación interior que permite que la vida fluya en un sentido más pleno y acorde con la realidad (SINAGA, 2005, p. 195).

Dejar ver una huella, una esencia familiar a través del vaciamiento del sujeto y de todo lo mundano conecta con la Cábala, el hermetismo, la alquimia y la psicología de las profundidades. Carl Jung, en la psicología analítica, define la "sombra" como doble o gemelo primitivo que reside en el inconsciente colectivo y que se compone de los caracteres reprimidos o no conscientes del yo. Es decir, el Yo sumido en la otredad, pero familiar. Sinaga desarrolla una oscuridad cercana, que se intuye pero que se resiste a la explicación, común a lo extrao inquietante en Freud o Unheimlich en Heidegger y los románticos nórdicos. Un nexo entre mística y arte en el enfrentamiento con la incomprensible inmensidad de la duda y el vacío no resuelto, ante una celosía que conduce a un lugar Otro.

Las sombras de Corazn Celado (Larvatus Prodeo) e Instante Fugaz, 2001 parecen querer advertirnos sobre los peligros que ellas mismas relatan. Sinaga, de forma autorretratística y oscura, se separa de su sombra. Su escenografía es un teatro sin engaño, una emoción subjetiva del fluir de la vida, los seres y las cosas. El alma, ejemplificada ya desde la mitología en la figura de la sombra, es representada como lo oculto. Como en las vánitas barrocas el tenebrismo que rodea tales obras connota que todo elemento, materia e imagen, es efímero y toda belleza es caduca. Toda sombra remite consciente o inconscientemente al "memento mori", (recuerda que vas a morir, recuerda que eres mortal, relativo a la fugacidad de la vida). La tragedia subyace bajo la relación entre la muerte y la sombra, la cual proviene del carácter de "doble", es decir, la imagen en "negativo" de un cuerpo expuesto a la luz, que posee ésta última en la representación occidental, la lógica platónica y el inconsciente colectivo.

\subsection{Receptivo}

Corazn Celado (Larvatus Prodeo) e Instante Fugaz necesitan de un estado perceptivo silencioso e íntimo para su recepción. Sin embargo, el camino hacia el Otro se demuestra im- 
posible, negado, disuelto. Es la resolución pospuesta de forma indefinida, provocando con ello la incomodidad del espectador. Aunque presentes, no podemos resolver definitivamente sus enigmas. Herméticas, desarrollan el problema de la incomunicación desde el silencio o más bien el grito mudo del plano visual al cual hace partícipe de sus inquietudes y anhelos, un elemento intrínseco al discurso moderno. Ad Reinhart lo tradujo como una negatividad que debía de protegerse, para que no se le obligue a concretarse, vulgarizarse o explotarse (Apud SINAGA, 1996, p. 39), apelando a la unidad perdida y la conciencia de lo individual.

En el libro La Era Neobarroca, Omar Calabrese subraya que en la contemporaneidad emerge lo extremadamente interrumpido, las figuras de lo discontinuo que provocan la comunicación irregular y el replanteamiento de la propia comunicación misma, como bien pueden ejemplificar las obras expuestas de Fernando Sinaga. Los títulos de las obras, Instante Fugaz y Corazn Celado (Larvatus Prodeo), concentran de manera sintética la poética de la forma, pero también son utilizados como forma de descentramiento, de puerta por la cual la obra también puede evadirse en la pluralidad de interpretaciones y referentes. Esto es posible porque en la actualidad el lenguaje es una herramienta indispensable para la producción y complementación de significados artísticos. El artista, como productor simbólico usa el texto bajo variados procesos reconstructivos para que encaminen la significación de la obra. Trabajo plástico y título acertado pasan a construir obras verbovisivas que comparten en estos tiempos la tarea de ofrecer un sentido abierto $y$, en mayor o menor medida, enigmático al conjunto.

De nuevo encontramos en Calabrese otra característica de este pensamiento en la sociedad y cultura actual: el deleite por lo oculto y el enredo. Un gusto general por una cierta pérdida de control para reencontrarnos en un orden re-estructurado y bajo la dinámica de la inestabilidad visual. La opción del espectador consiste en derivar en los significados de las obras, hacia un objetivo no resuelto, en suspenso y postergado en favor del enigma y la incertidumbre: la solucin al misterio es siempre inferior al misterio mismo. El misterio tiene que ver 
incluso con lo divino; la solucin, con un truco de prestidigitador (BORGES, 1981, p. 86).

Pero la raíz de esta continua necesidad de desvelar los misterios de la obra de arte procede justamente de esa pretendida naturaleza oculta y silenciosa que yace en el origen de las mismas, la cual, a su vez, provoca toda una serie de espacios simbólicos y emblemáticos. De nuevo, encontramos en el Barroco hispano, concretamente en sus inicios, la referencia más plausible a éste fuerte arraigo a la cultura simbólica.

\section{Conclusiones}

Tomando el Arte y sus obras como representantes de la cultura y la sociedad de una época y región determinada, en este caso la cultura contemporánea occidental, y tomando como muestra de la producción artística de las obras seleccionadas de Fernando Sinaga, las cuales se hayan inscritas en las estrategias más representativas y discursivas del arte del momento, podemos llegar plantear el reconocimiento de una serie de características predominantes, o espíritus, de éste tiempo:

4.1. Actualmente es sintomática la emergencia de un gusto neobarroco en la cultura contemporánea que, aunque no es totalitario, se manifiesta en el predominio de los niveles formal, semántico y receptivo que conllevan sus creaciones artísticas. Una de las estrategias representativas que mejor demuestra la afinidad cultural a esta tendencia neobarroca es la sombra.

4.2. A nivel formal las imágenes sombrías se comportan como medio de exploración de formas. Encadenan toda una serie de estrategias y recursos enunciados por Omar Calabrese en su libro La Era Neobarroca que ponen de relieve la pérdida de estabilidad y seguridad visual, la tendencia a lo asimétrico y distorsionado en sus estructuras formales y la apuesta por lo cambiante y fragmentado, en detrimento de los valores ordenados y normativos y las clásicas estrategias representativas miméticas e ilusionistas. 
4.3. A nivel semántico se desarrolla la capacidad de transgredir lo físico por lo simbólico y la narración múltiple. A lo largo de la investigación resaltan una serie de principios comunes como ausencia, vacío, apariencia, apertura, muerte, identidad o espera que nos hacen pensar en la simbología negativa intrínseca a las sombras de Fernando Sinaga heredadas ya desde Platón o la psicología de Jung. En sus obras la sombra construye ambigüedades y posibilidades interpretativas y referenciales abriendo el horizonte de la obra y activando la memoria y el imaginario sociocultural. Pero poseen el anhelo común de ir desvelando, debido a su alegoría de la duda, la relatividad y la metamorfosis, una era de complejidad e incertidumbre y que nos expulsa de nosotros mismos.

4.4. A nivel receptivo habría que destacar la capacidad de atracción y provocación hacia el espectador, y la importancia decisiva del receptor. Las sombras nacen y mueren en el vacío que encierran, se formulan como medio representativo abierto al sentir de las miradas. De aquí la importancia del receptor puesto deber ser él el que se apropie de la obra y que experimente la apertura y las posibilidades significativas. Esto afecta a la temporalidad de la obra, la cual queda aletargada hasta la resolución del receptor.

4.5. La mayor parte de este horizonte artístico depende de los continuos cambios de esta era. El polimorfismo, la masificación y la tecnocracia provocan la homogeneidad global en los discursos y, por oposición, la creación de fuerzas resistentes y centrífugas hacia lo heterogéneo.

4.6. De este modo, las estructuras neobarrocas exponen la desconfianza en la razón y en las verdades eternas del ser moderno y dibujan un marco cultural ecléctico, específico y abierto. Una época contemporánea paradójica y oscura que convive Notas

1. DUQUE, Félix. El Fulgor en lo Manifiesto. In: SINAGA, Fernando. Cor Duplex. Zaragoza: Museo Pablo Serrano, 2005, p. 9-10 


\section{Referencias}

BENJAMIN, Walter. Discursos interrumpidos. Madrid: Editorial Taurus, 1982.

BLANCO SALGUEIRO, Loreto; HERNANDEZ, Jesús; JIMENEZ, Inmaculada; MEANA MARTINEZ, Juan Carlos; NUÑEZ, Marina; RUIZ DE SAMANIEGO, Alberto. Contemplarse para comprenderse. Pontevedra: Diputación Provincial, Servicio de Publicaciones, 2004.

BORGES, Jorge Luis. El Aleph. Madrid: Alianza Editorial, 1981.

CALABRESE, Omar. La era neobarroca. Madrid: Editorial Cátedra, 1989.

EISNER, Lotte H. La Pantalla demonaca: las influencias de Max Reinhardt y del expresionismo. Madrid: Editorial Cátedra, 1996.

HABERMAS, J. ¿Aprender a fuerza de catástrofes? Diagnóstico retrospectivo del breve siglo XX. Revista La Balsa de Medusa, no 50, pp. 3-21, 1999.

MARIN VIADEL, Ricardo. La Investigacin en bellas artes: tres aproximaciones a un debate (Ricardo Marín Viadel, Juan Fernando de Laiglesia González de Peredo, José Luis Tolosa Marín). Granada: Grupo Editorial Universitario, 1998.

ROSENBLUM, Robert. La Pintura moderna y la tradicin del Romanticismo nrdico: de Friedrich a Rothko. Madrid: Alianza Editorial, 1993.

SINAGA, Fernando. Agua amarga. Mallorca: Fundación Pilar i Joan Miró, 1996.

SINAGA, Fernando. Anamnesis. Oviedo: Cajastur, Obra Social y Cultural, 2000.

SINAGA, Fernando. Cor duplex. Zaragoza: Museo Pablo Serrano, 2005.

SINAGA, Fernando. Consideraciones discontinuas y otras conversaciones. Salamanca: Domus Artium 2002. Fundación Salamanca, Ciudad de Cultura, 2006.

STOICHITA, Víctor. Breve historia de la sombra. Madrid: Editorial Siruela, 1999.

TANIZAKI, Junichiro. Elogio de la sombra. Madrid: Editorial Siruela, Madrid, 1995.

PRIGOGINE Ilya, STENGERS Isabelle. La nueva alianza: metamorfosis de la ciencia. Madrid: Alianza Editorial, 1994.

\section{FRAN MIGUENS FERRO}

Licenciado por la Facultad de Bellas Artes de Pontevedra, Universidad de Vigo (España), 2003. Actualmente prepara la tesis doctoral: "La sombra como procedimiento plástico en el arte contemporáneo", dirigida por D. Juan Carlos Meana Martínez, en el Departamento de Pintura de la Facultad de Bellas Artes de Pontevedra, Universidad de Vigo (España).

Email: cocleau@yahoo.es 